\title{
Opening the gates on US government data
}

$\mathrm{O}$

pen government initiatives can be a boon to public health research and patient-centred care but realizing the maximum benefit of such initiatives requires more than just dumping data online, say American policy wonks and health experts.

The United States is beginning to see returns on its two-year investment in open government, in large part because of policies and platforms implemented to ensure not only the quantity but also the quality and accessibility of the data released under the initiative.

US President Barack Obama unveiled an unprecedented Open Government Directive in December 2009, obligating federal departments and agencies to take concrete steps to open public access to information they maintained internally (www.whitehouse.gov/open/documents /open-government-directive).

The directive mandates department and major agencies to post "high-value" datasets to Data.gov, a national Web portal, in formats that would allow the public to download, search and reuse the information without restriction.

To date, thousands of collections have been registered at the site, including a comprehensive community health dataset from the Department of Health and Human Services containing a wealth of information on public health issues and indicators of health care quality, cost and access at the national, state and county levels.

"We released everything from deidentified federal payer data, to public health data from the Centers for Disease Control, to obesity risk factors and information on mortality for geographic regions such as counties," says Dr. Patrick Conway, former chief medical officer in the policy division at the Office of the Secretary at the Department of Health and Human Services. "Historically, some data had been available, but people didn't really use it."

Traditionally, government has taken a "top-down" or "transactional" approach to sharing information, a kind of one-way

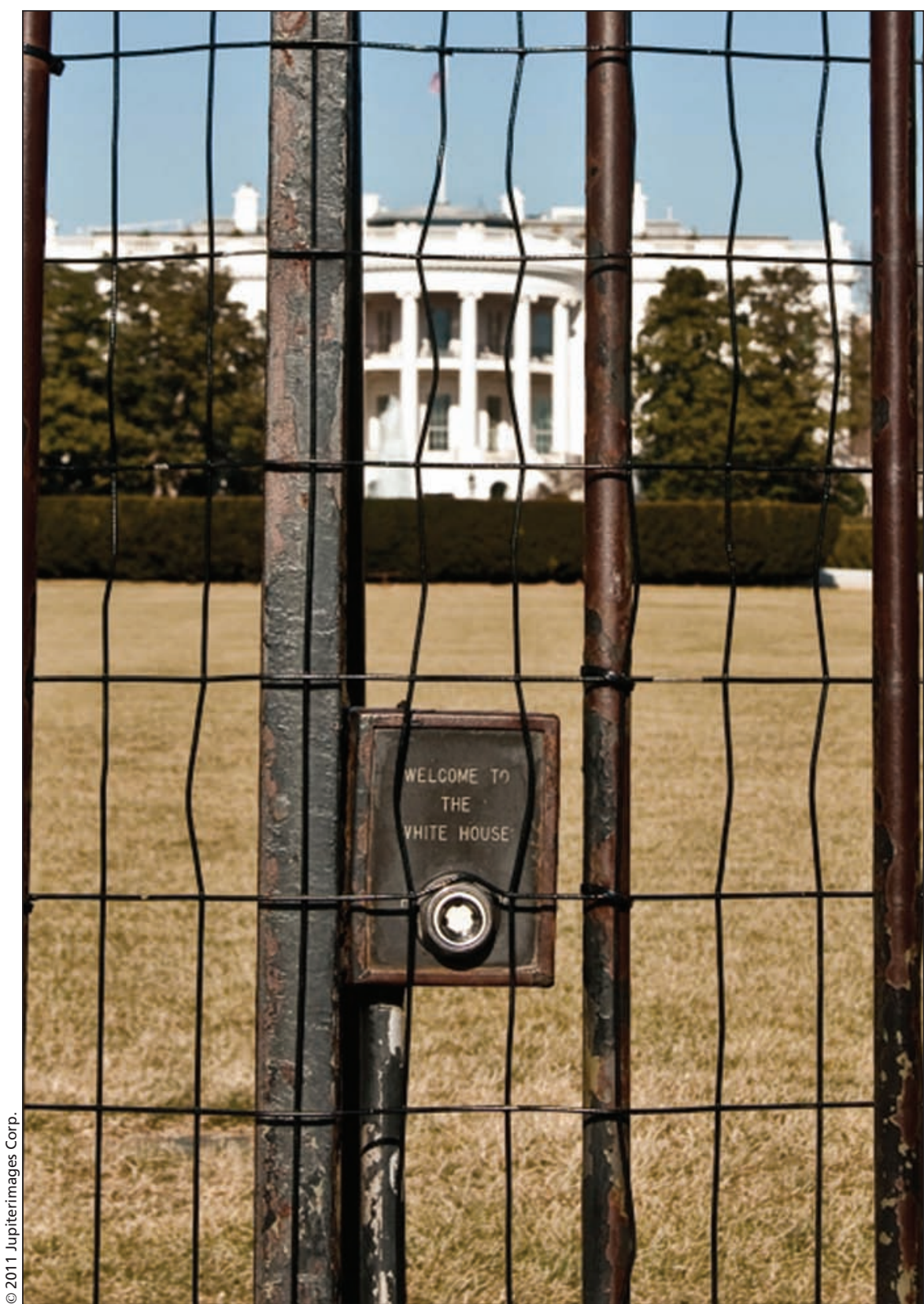

United States President Barack Obama's decision to bring government data from behind the gates to the public prompted technology companies, media, consumer advocates and others to develop tools to improve community health performance.

street where the user is a recipient or purchaser of "static" information, says Nicol Turner-Lee, vice president and director of the Media and Technology Institute at the Joint Center for Political and Economic Studies in Washington, DC. "As the Internet has evolved and we've seen the rise of social media, the way people are able to interact with information in the government space has to evolve, too."

Obama's directive was the first, good step toward a new "two-way, collaborative exchange" between citizens and their government, she adds. 
"The Open Government Initiative changed the paradigm," Conway says. "Now, it's not just about sharing as much data as possible, it's also about making it as user-friendly as possible, linking that data to search engines and applications to increase its use and potential to improve health."

The release of data quickly prompted technology companies, media, consumer advocates, employers and the general public to develop tools to improve community health performance. Within three months, some 24 innovations were developed using the raw community health data.

"One developer had a network of clinics give asthma patients inhalers with GPS tracking devices so they could track the use of rescue inhalers against environmental pollutant data, and develop a text messaging system to alert patients when they entered a high pollutant zone," Conway says. "Microsoft loaded hospital performance data into their search engine Bing, so that patients could look up hospitals in their area and immediately see the quality of care provided."

The paradigm shift is evidence that "open government goes far beyond transparency," former US deputy chief of technology Beth Noveck told the Canadian Parliament's standing committee on access to information, privacy and ethics in March (http://cairns.type pad.com/blog/2011/03/testimony-before -the-standing-committee-on-access-to -information-privacy-and-ethics-of-the -canadian-.html).

"It is important that government, together with the public, identify problems that need to be solved; publish data that enables the public to devise informed and creative solutions; and institute the platforms and the policies that enable collaboration by the people in their own governance," she added.

Information shared by government agencies such as the National Institutes of Health and the Food and Drug Administration are also a boon to researchers, enabling them to "build upon one another's work and make faster progress. The collaborators are achieving in record time together what no one company or researcher would have done alone," she noted, citing the "astonishing rapidity" of recent progress in charting the biological markers of Alzheimer disease in the human brain.

Such benefits, however, are largely dependent the quality and format of the data released, Noveck explained. Obama's directive required agencies to release "high-value" data, which was defined as "information that can be used to increase agency accountability ... improve public knowledge of the agency and its operations ... create economic opportunity ... or respond to need and demand as identified through public consultation."

Going beyond traditional forms of accountability data, such as spending data or the schedules of cabinet secretaries, creates "a widespread culture of change quickly" and ensures open government delivers "information that improves people's daily lives," she added.

It's "one thing to pay lip service to transparency and another to have a place to put data and make it findable and searchable," Noveck said. "So long as Freedom of Information, declassification and records management processes are entirely manual and data is created in analog instead of digital formats, open government will be very hard. Further, without tools to engage the public in brainstorming, drafting, policy reviews and the other activities of government, collaboration will elude us."

The initiative's success was in part predicated on a requirement that information be shared in a "machine-readable" format, allowing independent researchers and developers to conduct their own analyses and develop tools.

Other nations are now rapidly moving to follow the American lead. The British Parliament is debating amendments to its Freedom of Information Act that would obligate the government to provide information, when requested, "in an electronic form which is capable of re-use." Australia, Poland, Brazil, India and others are moving ahead with open government and open access policies.

In Canada, officials made a commitment to the Organisation for Economic Co-operation and Development in 2010 that the government would "launch a new portal to provide one-stop access to federal data sets" and implement a strategy "to fully incorporate Web 2.0 across the government" (www.oecd.org /dataoecd/48/56/46342001.pdf). Both the portal and the strategy have yet to materialize. - Lauren Vogel, CMAJ

CMAJ 2011. DOI:10.1503/cmaj.109-3839 